\title{
REVIEW
}

\section{Myelodysplasia is in the niche: novel concepts and emerging therapies}

\author{
E Bulycheva ${ }^{1}$, M Rauner ${ }^{2}$, H Medyouf ${ }^{3}$, I Theurl ${ }^{4}$, M Bornhäuser ${ }^{1,5}$, LC Hofbauer ${ }^{2,5}$ and U Platzbecker ${ }^{1}$
}

Myelodysplastic syndromes (MDSs) represent clonal disorders mainly of the elderly that are characterized by ineffective hematopoiesis and an increased risk of transformation into acute myeloid leukemia. The pathogenesis of MDS is thought to evolve from accumulation and selection of specific genetic or epigenetic events. Emerging evidence indicates that MDS is not solely a hematopoietic disease but rather affects the entire bone marrow microenvironment, including bone metabolism. Many of these cells, in particular mesenchymal stem and progenitor cells (MSPCs) and osteoblasts, express a number of adhesion molecules and secreted factors that regulate blood regeneration throughout life by contributing to hematopoietic stem and progenitor cell (HSPC) maintenance, self-renewal and differentiation. Several endocrine factors, such as erythropoietin, parathyroid hormone and estrogens, as well as deranged iron metabolism modulate these processes. Thus, interactions between MSPC and HSPC contribute to the pathogenesis of MDS and associated pathologies. A detailed understanding of these mechanisms may help to define novel targets for diagnosis and possibly therapy. In this review, we will discuss the scientific rationale of 'osteohematology' as an emerging research field in MDS and outline clinical implications.

Leukemia (2015) 29, 259-268; doi:10.1038/leu.2014.325

\section{DEFINITION AND COMPOSITION OF THE OSTEO-HEMATOPOIETIC NICHE}

Hematopoietic stem and progenitor cells (HSPCs) reside within the so-called 'bone marrow niches', which are defined as cellular and molecular microenvironments that cooperate with cell intrinsic mechanisms to maintain and regulate stem cell functions. ${ }^{1}$ The complexity of the niche is attributed to the fact that it simultaneously contains stem cells, precursor cells and terminally differentiated cells. HSPC represent precursors for osteoclasts (OCs) responsible for bone resorption, whereas mesenchymal stem and progenitor cells (MSPCs) progressively differentiate to give rise to mature osteoblasts (OBs) that produce the bone matrix. ${ }^{1}$ Below, we will summarize the role of bone cells and their respective progenitors, in particular, in the maintenance of the HSPC niche.

Mesenchymal stem cells and their progeny

Despite the established concept of the niche, there are still controversies concerning the composition and relevance of various compartments of the HSPC niche. OBs are considered key factors of the osteo-hematopoietic niche as transplanted HSPC often, but not always, lodge in close proximity to the bone trabecules. $^{2}$ Indeed, depletion of $\mathrm{MSPCs}^{3}$ or osteoblastic progenitors ${ }^{4}$ results in a decreased number of bone marrow HSPC. Similarly, the dependence of HSPC engraftment on the calcium-sensing receptor, ${ }^{5}$ as well as the ability of OB to produce several key cytokines and adhesion molecules, support the essential role of the osteoblastic lineage in maintaining hematopoiesis.
More recent studies have focused on dissecting the osteogenic HSPC niche. This has led to the identification of intermediate filament protein nestin-expressing MSPC and CXCL12-abundant reticular (CAR) cells, which are critical for niche homeostasis. ${ }^{6}$ Most of the nestin ${ }^{+}$cells $(60 \%)$ are found adjacent to HSPC both within and outside the endosteal region ${ }^{3}$ and highly express important genes for HSPC maintenance, such as CXCL12, interleukin-7 (IL-7), angiopoietin-1 and osteopontin. Deletion of CXCL12 from osterixexpressing stromal cells, which include CARs and OBs, results in constitutive HSPC mobilization, ${ }^{7}$ indicating that they have a critical role in maintaining HSPC self-renewal and differentiation. Nestin ${ }^{+}$ MSPCs, CAR cells, as well as recently described stem cell factorexpressing LepR+ cells are clearly important components of the HSPC niche, but the extent to which they may overlap is still under investigation. ${ }^{8}$ Moreover, it remains to be clarified which cell type requires direct contact with HSPC within the niche and which component acts through paracrine signals.

\section{OCs and their precursors}

OCs represent polynuclear HSPC-derived cells of the monocytic/ macrophagic lineage specialized in bone resorption. OCs modulate calcium and mineral balance, which affects the maintenance of HSPC. ${ }^{5}$ Functionally, OCs can degrade bone matrix and release numerous growth factors, including transforming growth factor $\beta$, into the bone marrow cavity. Moreover, OCs may directly modulate the mobilization of HSPC from the bone marrow to the circulation, ${ }^{9}$ both in normal and stress conditions, via cathepsin K-mediated cleavage of CXCL12. Experiments on osteopetrotic mice lacking OC demonstrated increased HSPC mobilization, thus

\footnotetext{
${ }^{1}$ Medizinische Klinik und Poliklinik I, Universitätsklinikum Carl-Gustav-Carus, Technische Universität, Dresden, Germany; ${ }^{2}$ Medizinische Klinik und Poliklinik III, Universitätsklinikum Carl-Gustav-Carus, Technische Universität, Dresden, Germany; ${ }^{3}$ Georg-Speyer-Haus, Institut for Tumor Biology and Experimental Therapy, 60596 , Frankfurt am Main, Germany; ${ }^{4}$ Department of Internal Medicine VI, Medical University of Innsbruck, Innsbruck, Austria and ${ }^{5}$ Center for Regenerative Therapies Dresden, Technical University, Dresden, Germany. Correspondence: Professor U Platzbecker, Medizinische Klinik und Poliklinik I, Universitätsklinikum Carl-Gustav-Carus, Fetscherstraße 74, Dresden 01307, Germany. E-mail: uwe.platzbecker@uniklinikum-dresden.de
} 
indicating bone resorbing cells as important regulators of the hematopoietic system. ${ }^{10}$ Interestingly, zoledronic acid, which is known to suppress OC activity, supports HSPC indirectly by increasing the secretion of bone morphogenetic proteins (BMP)-2 and -6 , which stimulate $O B$ functions. ${ }^{11}$ Importantly, niche formation is severely affected in the absence of $O C$ with reduced capacity of MSPCs to differentiate into OB and attract hematopoietic progenitors. ${ }^{12}$ This indicates that $O C$ have a critical role in the initial steps of the osteo-hematopoietic niche formation.

The OC progenitors, monocytes, are responsible for the protection of the HSPC pool from exhaustion both in steadystate conditions and during stress. ${ }^{13}$ They can be recruited from the blood circulation into the marrow, where they differentiate into macrophages and reside within the niche. Monocytes and macrophages are the main cells found in the bone marrow niche after irradiation, where they protect the HSPC pool from exhaustion by producing prostaglandin E2 to maintain undifferentiated primitive HSPC; loss of macrophages results in the egress of HSPC to the bloodstream. ${ }^{14}$ Moreover, macrophages also indirectly support HSPC through the modulation of the CXCR4CXCL12 axis. Prostaglandin E2, synthesized by macrophages, increases CXCL12 expression on nestin ${ }^{+}$stromal cells $^{13}$ and CXCR4 expression on primitive $\mathrm{HSPC}^{15}$ thus improving maintenance and survival of HSPC in the bone marrow. Importantly, macrophages represent an important link between HSPC and bone cells. Indeed, beyond their effect on hematopoiesis, macrophages stimulate proliferation and mineralization of $\mathrm{OB}$ and enhance the boneanabolic effect of parathyroid hormone (PTH). ${ }^{16}$

\section{IMPACT OF INTRINSIC AND EXTRINSIC FACTORS ON THE OSTEO-HEMATOPOIETIC NICHE}

The role of age

Functional properties of MSPCs are modulated by age and gender. ${ }^{17}$ In fact, Maijenburg et al. ${ }^{18}$ demonstrated that expression of MSPC surface markers, such as CD146, is age dependent. Interestingly, CD146 expression also depends on the proximity of MSPCs to certain bone compartments, with higher expression observed in perivascular niches, and lower levels in the osteoblastic niche. ${ }^{19}$ Moreover, a unique MSPC subset specific for fetal bone marrow has been identified. Currently, the reduced capacity of aged MSPCs to differentiate into OB is thought to be due to the deregulation of specific histone demethylases. ${ }^{20}$ Growth rate and clonogenic potential are substantially higher in MSPCs from younger female donors compared with aging counterparts. ${ }^{17,21}$ It could be partially explained by an increase in adipocyte number, which exhibits suppressive influence on hematopoiesis in aged bone marrow. ${ }^{20}$

Vice versa, coupling between HSPC functions and bone turnover during aging and development of osteoporosis is supported by the fact that HSPC are able to guide MSPCs toward the osteoblastic lineage through increased BMP-2 and -6 secretion, whereas this effect is diminished in aged mice. ${ }^{22}$ These observations suggest that the relative size and composition of niches are dynamic and require different types of MSPCs at different age periods.

\section{The role of PTH and cytokines}

The function of MSPCs and their progenies is modulated by several hormones (for example, PTH, estrogens) and local signals (for example, BMPs, Wnt). PTH is an approved polypeptide for the treatment of osteoporosis because it stimulates bone formation that results in increased bone mineral density with additional known effects on hematopoiesis. ${ }^{23}$ Indeed, PTH can directly stimulate the proliferation and survival of HSPC, but it also partially exerts its effects through the $\mathrm{OB}^{24}$ by increasing the production of Jagged 1 in $\mathrm{OB}$, which in turn activates Notch receptors on nearby
HSPC. Moreover, PTH has also been shown to act through the insulin-like growth factor pathway, which is specifically upregulated in OB, but not MSPCs in response to PTH. ${ }^{25}$ The effects of PTH on HSPC expansion are IL- 6 dependent, as they are lost in IL-6-deficient mice. Blocking IL-6 also attenuated PTH anabolic action on OB. ${ }^{26}$ Taken together, these data indicate that the effect of PTH through various molecules including IL-6 couples osteoblastic and hematopoietic activity.

At the local level, both the Wnt and BMP pathways are of crucial importance. ${ }^{27}$ Canonical Wnt/ $\beta$-catenin signaling pathway, specifically via Wnt3a, promotes proliferation of MSPCs and suppresses their osteogenic differentiation. ${ }^{28}$ At the same time, $\beta$-catenin inhibits formation of $\mathrm{OB}$ through increased osteoprotegerin expression. ${ }^{29}$ Wnt5a, a member of the non-canonical pathway, has been shown to suppress MSPC proliferation, but to increase the number of alkaline phosphatase-positive OB. ${ }^{30}$ This is further supported by the fact that Wnt inhibitory factor- 1 acts as a negative regulator of $\mathrm{OB}$ differentiation in mouse MSPCs. ${ }^{31}$ The non-canonical Wnt pathway also has a role in forming $\mathrm{OB}-\mathrm{OC}$ balance, as the upregulation of RANK by Wnt5a is a key step for osteoclastogenesis in response to receptor activator of nuclear factor kappa-B ligand (RANKL) secreted from OB. ${ }^{32}$ Importantly, lower Wnt-related transcripts in MSPCs are observed in old compared with young individuals, which may be a correlate of osteoporosis as an age-related disease. ${ }^{33}$

BMP- 6 is one of the most consistent and potent regulators of MSPC differentiation into OB as the lack of the $B m p 6$ gene caused a reduction of bone formation because of the $O B$ dysfunction. ${ }^{34}$ Moreover, systemic administration of BMP-6 restores the bone capacity by promoting MSPC differentiation toward $\mathrm{OB}$ and decreasing HSPC differentiation toward OC. ${ }^{35}$ Importantly, MSPCs can produce BMP-2, -4 and -6 in an autocrine manner that induce osteogenesis of marrow-derived MSPCs in vitro. ${ }^{36}$

In addition, autonomic neuronal regulation also modulates the osteo-hematopoietic niche (as reviewed by del Toro and MendezFerrer). ${ }^{37}$

The effects of erythropoietin (Epo)

Epo receptor expression has long been thought to be restricted to the erythroid lineage. However, Epo can also directly stimulate the formation of bone by inducing $O B$ differentiation and increasing mineral deposition. ${ }^{38}$ Experiments in vivo revealed that Epo first activates osteoclastogenesis, which is later followed by osteoblastogenesis either directly or via HSPC-mediated BMP secretion. These seemingly opposing effects of Epo on bone loss and formation have been shown to be context dependent. In developing or in BMP-driven bone regeneration, Epo increases bone formation by increasing bone remodeling, whereas it increases bone resorption rather than bone formation in mature and old bones. ${ }^{39}$ Although the molecular mechanisms remain poorly defined, recent data suggest that mammalian target of rapamycin signaling may have a role in Epo-mediated OBs and OCs formation. ${ }^{40}$ The rapid loss of trabecular bone volume observed after Epo exposure in mice ${ }^{41}$ is believed to be driven by a release of oncostatin $M$ from erythroblasts, which in turn induces OB to secrete RANKL thereby potentiating OC maturation. Moreover, zoledronic acid, which is a known molecule that inhibits OC formation and function, completely blocked Epo-induced decrease in bone, indicating the involvement of OC in this Epomediated process. Importantly, bone remodeling is crucial for a normal erythropoietic response to Epo, as bisphosphonate treatment also reduced the magnitude of the erythroid response to Epo.

Epo-releasing scaffolds showed induction of chemotaxis of MSPCs and their pro-osteogenic differentiation. ${ }^{42}$ MSPC motility was also increased after Epo exposure. ${ }^{43}$ Furthermore, in vivo implementation of Epo loaded scaffolds showed that they 
promote osteogenic activity. It is also important to mention that OBs are also capable of driving erythropoiesis by their ability to produce Epo. ${ }^{44}$ Together these data demonstrate an intimate coupling between hematopoiesis and bone formation through Epo.

\section{THE IMPACT OF THE OSTEO-HEMATOPOIETIC NICHE ON THE PATHOGENESIS OF MDS}

The pathogenesis of myelodysplastic syndrome (MDS) is thought to be due to an altered phenotype of the HSPC compartment as a result of genetic instability and disease-modifying mutations. There are several well-described somatic genetic abnormalities, which are commonly, although not exclusively, found in MDS. At least one genomic alteration can be found in 78\% of MDS patients, with genes involved in RNA splicing (SF3B1, SRSF2) to be the most common and the earliest in disease evolution. ${ }^{45}$ Intriguingly, these early mutations could also influence the further development of the disease, as later cooperating mutations are shown to be different between these two genes, despite the fact that they are both involved in the same pathway. Finally, some data support the notion that the disease phenotype may be closely linked to the mutation profile. Indeed, SF3B1 is associated with the presence of ring sideroblasts, whereas SRSF2 mutation is more commonly observed in chronic myelomonocytic leukemia. ${ }^{46}$

Although the most important event in MDS pathology appears to be a molecular defect in HSPC, evidence suggests that ineffective hematopoiesis may also result from abnormalities in the bone marrow microenvironment, including altered hematopoietic-stromal interactions and deregulated production of growth factors and hematopoietic modulators (Figure 1).

\section{Preclinical models}

Animal models represent powerful tools to model and study human diseases and are useful preclinical platforms. Several mouse models have been generated to represent MDS pathology. Most of them are connected with the mutations in HSPCs (Evi-1 overexpression, Npm1 hetero mice, Nup98/HoxD3 transgenic mice, mutated Aml1, microRNAs-145 and 146a knockdown). ${ }^{47-50}$ NUP98HOXD13 transgenic mice represent among others a very accurate preclinical model. The NUP98 gene is found to be affected in chromosomal translocations commonly seen in MDS. Mice with this phenotype develop all of the key features of MDS, including peripheral blood cytopenias, bone marrow dysplasia, impaired differentiation of early hematopoietic progenitors and transformation to acute leukemia. ${ }^{51}$ The most recently developed mouse models have the merit of combining genetic events that are found in the HSPC of patients with MDS, such as concurrent loss of Ezh2 and $T e t 2,{ }^{52}$ deletion of $A s \times 11^{53}$ and haploinsufficiency of SAMD9L mimicking monosomy $7 .^{54}$ However, given the tremendous heterogeneity of MDS in patients, it is likely that no single genetic mouse model can recapitulate all the subtypes at once and therefore patient-specific models using xenografts would be highly valuable tool to study the biology of human MDS.

One noteworthy model of MDS/myeloproliferative neoplasm is connected with the deregulation of Wnt canonical pathway. After serial transplantations of HSPC with loss of the APC gene, which is a known negative regulator of Wnt pathway, mice developed an MDS/myeloproliferative neoplasm phenotype. APC is a tumor suppressor located on human chromosome $5 q$, which indicates that this model can be attributed to the well-known $5 q-$ syndrome. ${ }^{55}$

Another model represents microenvironment-induced myelodysplasia with Dicer1 deletion in osteoprogenitors. Raaijmakers et $a .^{56}$ have provided evidence for the first time that a disturbance of the endosteal niche can result in MDS. Deletion of Dicer1-an RNase III endonuclease essential for microRNA biogenesis and a

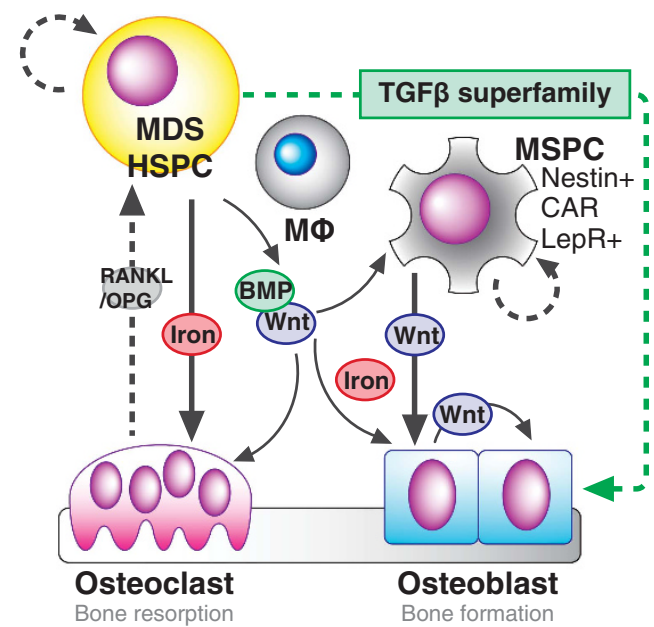

b

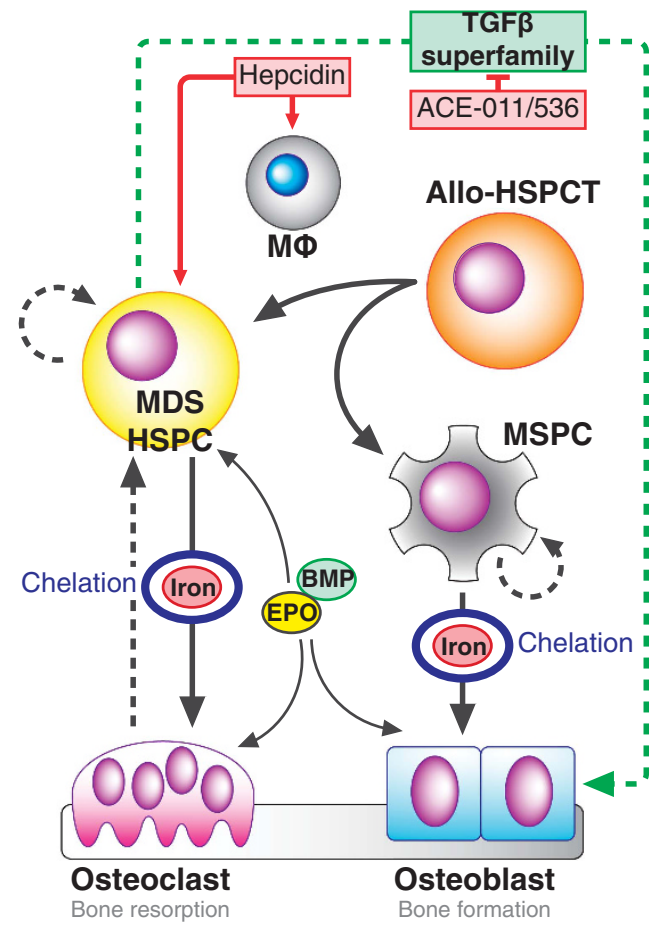

Figure 1. (a) Cellular and humoral components within the osteohematopoietic niche. Lines, differentiation/self-renewal, dash-lines, signaling pathways. (b) Potential therapeutic targets in modulating the osteo-hematopoietic niche of patients with MDS. Allo-HSPCT, allogeneic HSPCT; OPG, osteoprotegerin; TGF $\beta$, transforming growth factor $\beta$; Wnt, Wnt signaling pathways.

RNA processing in mouse osteoprogenitors, but not in mature $\mathrm{OB}$ disrupts the integrity of hematopoiesis. OB number was significantly decreased, whereas $O C$ number and function was not affected. These mice developed fatal neutropenia with hyperplastic bone marrow and dysmyelopoiesis, which is highly suggestive of MDS. When transplanted into wild-type recipient mice, these MDS cells were not able to propagate the disease, suggesting that this phenotype was not cell autonomous. Conversely, when Dicer knock-out mice were reconstituted with bone marrow cells from wild-type mice they developed MDS, thus demonstrating the essential role of the niche in instructing HSPC to acquire an MDS phenotype. Interestingly, MSPCs isolated from MDS patients also 
exhibit a low expression of Dicer1 and DROSHA-another RNA III endonuclease, as well as a global downregulation of microRNA expression. $^{57}$

Although genetic mouse models strongly argue in favor of a critical role of the bone marrow niche, translation of these findings to human MDS remains highly speculative. A recent study, however, has provided the first proof of concept that patientderived stromal cells have a crucial role in the propagation of human MDS stem cells in vivo, thus establishing a robust xenograft model of lower-risk MDS. ${ }^{58}$ Indeed the authors showed in a cohort of lower-risk MDS cases with different genetic makeup that co-injection of patient-derived CD34+ cells and the corresponding MSPCs into the bone marrow cavity of immunocompromised mice, lead to long-term and significant engraftment of bone fide MDS cells, as demonstrated by a strong myeloid bias and clonality tracking. In contrast, injection of CD34+ cells alone was highly inefficient; especially in the context of lower-risk MDS, as previously reported by others. ${ }^{59}$ Interestingly, the properties of cotransfused MSPCs appear to be of importance, as patient-derived MSPCs were more efficient, than healthy age-matched MSPCs, in supporting MDS stem cells. Importantly, the authors also provided experimental evidence that a number of processes involved in cellular cross-talk were deregulated in MDS-MSPCs, some of which are instructively imposed by the diseased hematopoietic cells. Taken together, these data argue in favor of the view that stromal niche elements likely contribute to MDS pathogenesis, and that the bi-directional cross-talk may lead to yet to be defined stepwise events that may very well facilitate disease progression. Finally, the fact that specific MSPCs properties are important for MDS propagation, is also supported by the fact that cells with overexpression of CD146 (MCAM) exhibit an increased ability to support short-term (5-13 weeks) MDS engraftment and propagation (mostly higher risk cases), when compared with their cytokine-secreting counterparts. $^{60}$

Alterations of the cellular components of the niche in patients with MDS

Published data on the involvement of the cellular components of the 'niche' are summarized in Table 1. The majority have demonstrated alterations of niche cells. The first report revealed decreased $O B$ and $O C$ numbers and bone formation rate. ${ }^{61}$ Multiple data have shown that osteoprogenitors-MSPCsexhibit normal morphology and frequency in the bone marrow of MDS patients, ${ }^{62}$ as well as undisturbed osteoblastic, adipocytic and chondrocytic differentiation potential in vitro. Similarly, MDS-MSPCs were reported to support the in vitro growth of MDS-derived HSPC. ${ }^{63,64}$ In contrast, other groups demonstrated reduced osteogenic differentiation and low ability to support hematopoiesis in long-term culture-initiating cells assays. ${ }^{65,66} \mathrm{~A}$ probable role of the chemokine CCL3 secreted by malignant cells in this process is suggested. ${ }^{67}$
Antigen expression of adhesion molecules on the cell surface of MDS-MSPCs does not seem to differ from the normal counterparts, although some authors have postulated significantly lower expression level of CD90 and CD105. ${ }^{6,69}$ CD49b-an integrin involved in the interaction of MSPCs and collagen type $\mathrm{I}$-is expressed at a higher level that can implicate changes in extracellular matrix synthesis and MSPC growth defects. ${ }^{63,70}$ MSPCs display a more widespread expression of CXCL12 in MDS, which may expose HSPC to increased contact-mediated signaling with CXCL12-expressing cells. Thus, these stromal cells fail to support trafficking of maturing hematopoietic cells to the microenvironment compartments. ${ }^{71}$ On the other hand, CXCR4 expression on HSPC has been found to be downregulated in MDS that could be successfully corrected by treatment with lenalidomide. $^{72}$

Various cytogenetic abnormalities have been shown to be present in MSPCs of up to $50 \%$ of patients with MDS, which are different from those detectable in the HSPC compartment. ${ }^{73}$ Chromosomes 1 and 7 were shown to be more frequently involved in MSPC structural aberrations and a correlation between aberrations in MSPCs and overall survival has been published. ${ }^{74}$ The presence of chromosomal abnormalities (mainly aneuploidy) in MDS-MSPCs is associated with the deregulated expression of AURKA and AURKB genes. ${ }^{75}$ Thus, the presence of genetic abnormalities in MSPCs suggests that a genetic instability of the bone marrow microenvironment may facilitate the expansion of malignant cells and be, therefore, a particular mediator of leukemogenesis.

Other important cellular components, which can contribute to the disturbance of the hematopoietic niche, are monocytes and macrophages. In fact, monocytes from patients with MDS are derived from clonal HSPC and fail to upregulate matrix metalloproteinase-9 (MMP-9) gene expression in response to stromal signals. ${ }^{76}$ Given the role of MMP-9 in facilitating the egress of cells from the bone marrow, it is reasonable to assume that non-responsive monocytes accumulate over time, whereas inducible levels of MMP-9 decline, thus resulting in hypercellularity in the bone marrow of patients with MDS. Macrophages can interrupt the normal interaction between MSPCs and hematopoietic progenitors in MDS through increased synthesis of tumor necrosis factor-a. ${ }^{77}$ Moreover, macrophages represent target cells of iron deposition during transfusion-associated iron overload, which may further impair their function. Clearly, a better delineation of signaling pathways responsible for altered responses between stromal cells, macrophages and HSPC, as well as the activities that trigger these pathways in MDS are needed.

Impact of disturbed signaling within the osteo-hematopoietic niche

The issue of secreted cytokines and adhesion molecules in MDS is controversial, as some groups claim no difference in cytokine

Table 1. Overview of published data on the potential role of MSPCs and derivates in the pathogenesis of MDS

$\begin{array}{lll}P R O S & \text { CONS }\end{array}$

- Cytogenetic aberrations in MDS-MSPCs $s^{62,63,74}$

- Lower expression of Dicer1, DROSHA, ${ }^{56,57}$ AURKA, AURKB ${ }^{75}$ genes in MDS-MSPCs

- Altered immunophenotype in MDS-MSPCs: decreased CD44 and CD49e, ${ }^{70}$ CD90, CD104 and CD105 ${ }^{68}$ expression, increased CXCL12 expression ${ }^{71}$

- Impaired proliferation and differentiation capacity of MDS-MSPCs ${ }^{58,65,70}$

- Impaired cytokine production, including IL-32, by MDS-MSPC ${ }^{58}$

- Deregulation of Wnt signaling pathway in MDS-MSPCs ${ }^{82,89}$

- Impaired HSPC support by MDS-MSPC ${ }^{65,66}$
- Normal cytogenetics in MDS-MSPCs ${ }^{64,66}$

- Normal structure, proliferation and differentiation potential of MDS-MSPCs ${ }^{62,63,64,66}$

- Normal HSC support by MDS-MSPCs ${ }^{62,63,64}$

Abbreviations: HSPC, hematopoietic stem and progenitor cell; IL-32, interleukin-32; MDS, Myelodysplastic syndrome; MSPC, mesenchymal stem and progenitor cell. 
status between MDS patients and healthy donors, whereas the others demonstrate profound deregulation of secretion of vascular endothelial growth factor, leukemia inhibitory factor and so on and highly upregulated N-cadherin expression in MDSMSPCs. ${ }^{58}$ An increased production of IL- $1 \beta$ and stem cell factor was observed in response to tumor necrosis factor-a stimulation, ${ }^{78}$ whereas tumor necrosis factor-a secretion itself induced conflicting data ${ }^{63}$ with a proposal of its possible role together with interferon- $\gamma$ in disease progression. ${ }^{79}$

The impact of deregulated Wnt signaling in MSPCs on MDS pathogenesis remains largely elusive. Genes encoding known Wnt antagonists have been shown to be hypermethylated ${ }^{80}$ in patients with MDS, suggesting a direct correlation between methylation status and risk of leukemia evolution. ${ }^{81}$ On the other hand, global gene expression profiling showed a significant downregulation of genes involved in canonical Wnt signaling, especially in the $5 q-$ syndrome. This data led to the hypothesis that the imbalance between canonical and non-canonical Wnt signaling may contribute to the defective self-renewal of HSPC. ${ }^{82}$ This altered signaling is also suspected to have a role in iron regulation and appears to be an important factor in MDS pathogenesis, which requires further studies. Of note, deregulation of Wnt signaling not only affects HSPC, but also has an influence on the bone marrow niche. ${ }^{83}$ As such, overexpression of various Wnt-inhibitors in $\mathrm{OB}$ exhibits a dual effect by altering the niche architecture with the reduction in trabecular bone and affecting hematopoietic progenitor cells, ${ }^{84-86}$ both impairing their localization and function within the bone marrow. ${ }^{87}$ Depletion of iron can activate Wnt/ $\beta$ catenin pathway and induce osteoblastic differentiation of MSPCs. ${ }^{88}$ However, it remains to be seen whether this has implications in the clinical setting, when iron chelation is administered to MDS patients. Importantly, activating mutation of $\beta$-catenin in $O B$, also found in patients with MDS, led to the increased synthesis of Notch ligand Jagged 1, which in turn activates Notch signaling in HSPC, leading to alteration of differentiation potential of hematopoietic progenitors and acute myeloid leukemia development. ${ }^{89}$ This coupling of stromal and hematopoietic signaling pathways clearly highlights the need for developing new strategies aiming at disrupting this pathological niche-hematopoietic cell interaction.

Deregulation of the Epo signaling pathway may also be involved in hematopoietic niche alterations. The fact that Epo analogs induce erythroid responses in only up to $40 \%$ of unselected patients with lower-risk MDS $^{90}$ can be explained in part by the observation that most patients already have elevated Epo serum levels as a result of inefficient hematopoiesis. It is speculative to consider that the continuous and sometimes excessive elevation of endogenous Epo levels may lead to alterations of the bone microenvironment. Moreover, MDS HSPC exhibit an altered signaling in response to Epo in MDS, ${ }^{91}$ suggesting that HSPC-derived OC could also mediate this process. It is also conceivable that Epo may promote the production of other OB- or OC-stimulating proteins such as Wnt proteins or RANKL. Increased levels of circulating Epo and decreased sensitivity of erythroid progenitors to this factor have been found in TfR2 - / - mice, used as a model of iron overload. In fact, TfR2 is a component of the Epo receptor complex, ${ }^{92}$ which may imply that Epo is involved in the process leading to iron overload in MDS patients.

The role of iron overload and disturbed iron homeostasis

The idea that iron metabolism is involved in the regulation and alteration of the bone marrow niche is based on several lines of evidence. First, iron overload is very common in MDS-both because of blood transfusions and inefficient erythropoiesis itself. Second, in general, iron overload is widely regarded as a risk factor for osteopenia and osteoporosis, as it has been shown to inhibit osteoblastic differentiation and increase osteoclastic differentiation, potentiating bone resorption. Finally, osteoporosis is a very common complication of other diseases connected with iron overload, such as sickle cell anemia, thalassemia and hemochromatosis.

Defects in bone regulation in case of iron overload can be observed at various levels. Even in the most primitive non-cellular model, growth of hydroxyapatite crystals was inhibited because iron binds tightly phosphate groups and thus affects the nature of precipitates. $^{93}$

Several studies indicate adverse effects of iron overload on bone homeostasis. Precursors of $\mathrm{OB}$ are able to incorporate iron particles and inorganic iron, and both transferrin and ferritin were capable to inhibit alkaline phosphatase activity, a major enzyme required for proper $O B$ function. Iron overload also suppressed OB-specific gene expression, such as osteocalcin, osterix and Runx2, in a dose-dependent manner. Thus, iron itself can inhibit essential OB functions such as bone formation. ${ }^{94}$ These observations were confirmed at the organism level by creating an iron overload in HFE gene knock-out mice, representing the model of hereditary hemochromatosis. These mice exhibited a significant decrease in bone mineral density even when iron overload was mild. ${ }^{95}$ However, changes in the functional capacity of the hematopoietic system were not investigated. The iron deterioration of OB activity can, at least partially, be mediated by ferritin and its ferroxidase activity, which inhibited the calcification, whereas mutant ferritin lacking ferroxidase activity failed to provide any inhibition. ${ }^{96}$ The main component of the nontransferrin bound iron-labile plasma iron-is responsible for the formation of free radicals, which can lead to cell damage. The importance of oxidative stress in labile plasma iron-mediated toxicity was demonstrated in an experiment with iron-overloaded mice mimicking transfusional siderosis: increased reactive oxygen species (ROS) correlated with the severity of iron overload and thinning and alteration in the material properties of the bone. The prevention of bone abnormalities with the antioxidants supports the idea that oxidative stress is involved in the pathogenesis of the bone loss during iron excess. ${ }^{97}$

Importantly, OC have also been found to be involved in the deterioration of the bone structure and function during iron overload. ${ }^{97}$ Ferric application enhanced the formation of tartratresistant acid phosphatase-positive mononuclear cells from pre-OC cell lines in a dose-dependent manner, ${ }^{98}$ whereas the treatment with iron chelators induced inhibition of osteoclastogenesis. ${ }^{99}$ One of the mechanisms connected with these effects is also attributed to the formation of ROS. ${ }^{100}$ Iron treatment alone or together with RANKL increased intracellular ROS in pre-OCs and therefore led to oxidative stress, which favored OC differentiation, whereas the treatment with antioxidants could neutralize these effects. ROS, induced by iron application, could also upregulate RANKL mRNA, but had little effect on osteoprotegerin, therefore again favoring OC development. ${ }^{98}$

In the process of iron overload, an altered production of hepcidin has been postulated to have an important role. Although early data about rate of hepcidin excretion in patients with MDS were rather conflicting, ${ }^{101,102}$ recent analysis clearly showed that mean hepcidin levels are very heterogenous and depend on MDS subtype with the lowest level in refractory anemia with ringed sideroblasts and the highest in refractory anemia with excess blasts and chronic myelomonocytic leukemia. ${ }^{103}$ These data are in concordance with an in vitro study showing a prominent variability in the ability of serum from MDS patients to suppress hepcidin expression in hepatocytes. ${ }^{104}$

Thus, there are convincing studies highlighting a potential role of iron in the modulation of several components of the osteohematopoietic niche. However, whether iron overload or depletion is able to significantly alter the cross-talk of hematopoietic cells with the microenvironment in MDS has not been yet 
investigated in details. Clearly, more research is required to assess this in preclinical and clinical studies.

\section{PROPOSAL OF 'OSTEOHEMATOLOGY' AS A HOLISTIC APPROACH IN MYELODYSPLASIA}

The existence of complex interactions between hematopoietic cells and their niche has been documented manifold and provides a rationale for developing a holistic approach, when it comes to treating pathologies of the osteo-hematopoietic niche, such as MDS. Concomitance of higher incidence of MDS in old individuals and age-related alterations of bone structure and function supports this idea. Further, multiple alterations of key signaling pathways are common in both types of cells, which proposes that a better understanding of the disease pathology may facilitate the development of effective therapeutic targets.

Potential therapeutic targeting of the osteo-hematopoetic niche The proposal of osteohematology provides a new concept of possible concurrent medical impact on both hematopoietic and stromal cells in MDS (and other diseases like multiple myeloma). One of the best examples of an osteo-hematological approach can be demonstrated by means of allogeneic HSPC transplantation (HSPCT). Engraftment and maturation of donor-derived multipotent HSPC defines the success of this approach. The prerequisite for that is an appropriate milieu provided by a competent bone marrow microenvironment, which is chimeric following allogeneic HSPCT, containing recipient MSPC-derived cells and monocytes/macrophages, which may remain iron overloaded. Thus, when allogeneic stem cells are infused, they encounter a microenvironment, which is possibly impaired for a sustained period of time. This may in part explain the higher rates of graft failure and relapse as well as the prolonged time to stable engraftment seen in MDS patients mainly after HSPCT with reduced intensity conditioning. Given the long-term engraftment in this group of patients, irreversible MSPC defects seem rather unlikely and the problems are probably more related to disturbed cross-talks between hematopoietic cells and the bone microenvironment. On the other hand, allogeneic HSPCT may reprogram the microenvironment by modulating other HSPC-derived compartments including OCs. Comparative analyses on the functional capacity of the microenvironment in MDS before and after allogeneic HSPCT are not yet available.

Other therapeutic approaches, which are approved or currently in clinical studies, for MDS treatment are listed in Table 2. Two hypomethylating agents-azacitidine and decitabine-which were originally thought to affect only the defective leukemic clone are now shown to have an influence also on the bone cells. As such, azacitidine inhibits the Wnt signaling pathway in MDS cells and may improve bone metabolism as well. ${ }^{105}$ Further, hypomethylating agent could increase expression of BMP molecules in $\mathrm{OB}$, thus potentially favoring the process of bone formation compared with bone resorption. ${ }^{106}$

The most prominent example of potential simultaneous effect represents the activin receptor type II ligand trap sotatercept (ACE-011). ${ }^{107}$ It represents a chimeric protein, which consists of extracellular domain of the ActRIIA receptor and Fc portion of the human immunoglobulin $G$ antibody. Its main action is antagonizing activin and other ligands of the transforming growth factor $\beta$ family and interfering with downstream signaling cascades, mainly the SMAD pathway. Activin levels correlate with bone lesions and in the preclinical studies ACE-011 increased bone formation, mineral density and strength of trabecular bone in monkeys. ${ }^{108}$ Concurrent prevention of paclitaxel-induced anemia in murine models, ${ }^{109}$ as well as observed increase in hemoglobin in patients, treated with this drug for postmenopausal osteoporosis $^{110}$ and myeloma bone lesions, ${ }^{111}$ led to the idea that ACE-011 could have an impact on erythropoiesis either directly or by modifying the functions of bone cells. However, it does not affect differentiation of erythroid progenitors or precursors directly, thus this effect is expected to be mediated by factors present within bone marrow niche. ${ }^{112,113}$ Indeed, stromal cells showed alterations in the expression of various important genes and cytokines in response to the drug. ${ }^{113}$

The analogous molecule ACE-536 (luspatercept) is a related compound targeting preferentially growth differentiation factor- 8 and growth differentiation factor-11. It corrects the anemia associated with ineffective erythropoiesis in abovementioned NUP98-HOXD13 murine model. ${ }^{114}$ Importantly, both ACE-011 and ACE-536 promote maturation of late-staged Epo-independent erythroid precursors. Co-treatment with Epo induced synergistic responses, which provides a rational for a combination therapy in patients with MDS-related anemia. ${ }^{112}$ Interestingly, RAP-011 (murine ortholog of ACE-011) itself increased plasma levels of Epo, indicating that regulation of erythropoiesis by RAP-011 may not be limited to its activity within the bone marrow microenvironment. ${ }^{112}$ These findings indicate that sotatercept/ ACE-011 and ACE-536 may represent effective treatments for impaired erythropoiesis in MDS with concomitant alterations of the osteo-hematopoietic niche. Currently, two clinical trials are

Table 2. Currently available therapeutic options for patients with MDS and their potential impact on the functional properties of the osteohematopoietic niche

\begin{tabular}{|c|c|}
\hline Agent & Mechanism \\
\hline HMA (azacitidine/decitabine) & $\begin{array}{l}\text { * Demethylation of Wnt-antagonist gene promoters and reduction of the non-phosphorylated } \beta \text {-catenin in } \\
\text { * USPCs } \\
\text { Upregulation of BMP-2, }-4 \text { and }-6 \text { expression in osteoblasts }\end{array}$ \\
\hline Lenalidomide & $\begin{array}{l}\text { * Inhibiting angiogenesis, suppressing the production of proinflammatory cytokines (for example, TNF } \alpha \text { ), } \\
\text { inhibiting cytokinesis in MDS cell lines } \\
\text { * Decrease of CXCL12 secretion by MSPCs, thereby detaching HSPC from their niche; enhancement of CD29 } \\
\text { (integrin } \beta 1 \text { ) expression } 69 \\
\text { * Increase in expression of adhesion molecules in HSPCs; increase in CXCL12 and ICAM-1 secretion by MSPCs, thus } \\
\text { improving their hematopoiesis-supporting capacity }\end{array}$ \\
\hline ACE-011/ACE-536 & $\begin{array}{l}\text { * Trap of important soluble factors (that is, activin, BMP-2, BMP-6) secreted by stromal cells }{ }^{107,112} \\
\text { * Modulating of the SMAD signaling pathway, which leads to changes in the transcription of SMAD-regulated } \\
\text { target genes }{ }^{113}\end{array}$ \\
\hline Iron chelation & * Activation of Wnt $/ \beta$-catenin pathway and induction of osteoblastic differentiation of MSPCs ${ }^{117}$ \\
\hline
\end{tabular}


recruiting patients to evaluate the effect of activin receptor type II ligand trap on anemia in patients diagnosed with low- or intermediate-1 risk MDS (ACE-011/sotatercept-NCT01736683; ACE-536/luspatercept-NCT01749514) and preliminary data suggest clinical activity. ${ }^{115}$

Another approach to interfere with the osteo-hematopoietic niche in MDS may be through counteracting the phenomenon of iron overload. The mainstay of systemic iron overload treatment is iron chelation; however, treatment efficacy is compromised by suboptimal compliance and drug toxicity. Iron chelation seems to be important because of its role in improving hematopoiesis. Recent data suggest that iron chelation could even lead to the hematologic improvement in some patients. ${ }^{116}$ Various mechanisms have been proposed to mediate this effect, such as reduced oxidative stress and improved stromal support. ${ }^{17}$ Indeed, deferoxamine could partially attenuate MSPCs injury and inhibit signaling pathways induced by excessive iron. A role for iron chelation in the improvement of stromal cells function and their ability to support hematopoiesis is yet to be reported.

Novel agents, which influence the hepcidin-ferroportin axis, including exogenous hepcidin, transferrin, hepcidin analogs and signaling agonists, could provide an effective alternative. So far, in a mouse model of ineffective erythropoiesis the systemic transferrin application improved red blood cell survival and, most importantly, normalized the level of labile plasma iron. ${ }^{118}$ Furthermore, hepcidin and its analogs are attracting more attention as potential agents to treat iron overload and improve erythropoiesis. When HFE knock-out mice, representing parenchymal iron overload, were crossed with transgenic mice constitutively overexpressing hepcidin, iron accumulation was completely prevented. ${ }^{119}$ Synthetized minihepcidins showed an improved potency and longer action in comparison with natural hepcidin, its efficacy in iron depletion in mice raises the possibility of its potential usage in humans.

Another appealing approach, which couples iron homeostasis and bone physiology, is the treatment with BMP-6, which in cooperation with its receptor acts as an 'iron-sensing' system. Administration of BMPs, as well as upregulation of the BMP-6 signaling has shown not only in vitro, but also in vivo promising results in increasing hepcidin and reducing serum iron level. ${ }^{120}$ Thus, members of this group of molecules, being at the same time the stimulators of the osteogenic differentiation of MSPCs, could be considered as the stimulants of hepcidin synthesis through targeting the BMP/SMAD signaling pathway.

In general, the regulation of hepcidin-ferroportin system could be an important approach in iron overload accompanying MDS, but the side effects, such as iron deficiency or excessive calcification should be avoided.

\section{CONCLUDING REMARKS}

The concept of 'osteohematology' provides a novel view onto the processes occurring within the bone marrow and raises new paradigms for pathomechanisms of hematological and skeletal diseases. MDS in particular, represents a disease with vivid interactions within the osteo-hematopoietic niche and the contribution of the niche has only recently been appreciated. Thus, treatment strategies need to be developed that not only target the leukemic cells, but also the signaling pathways connecting both sides to provide a holistic and effective approach to this disease.

\section{CONFLICT OF INTEREST}

The authors have received grants or honorarium for advisory boards or lectures to the individual or the institution by Novartis (UP and LCH), and Celgene (MB and UP). UP is supported by a grant within the DKTK; UP, MB and LCH are supported by a grant within the SFB 655 from the Deutsche Forschungsgemeinschaft (DFG); UP and
MR are supported by a grant from the Jose Carreras foundation and LCH and MR are supported by a seed grant from the CRTD. HM is supported by a Jose Carreras Career Award (DJCLS A 13/01).

\section{ACKNOWLEDGEMENTS}

We apologize to the many original contributions in the field that could not be cited because of manuscript limitations. We thank S Helas and Alexey A Soshnev for assistance in formatting the figures.

\section{AUTHOR CONTRIBUTIONS}

$E B, L C H$ and UP drafted the manuscript. All other authors critically read and edited the paper. EB and MR contributed equally.

\section{REFERENCES}

1 Morrison SJ, Scadden DT. The bone marrow niche for haematopoietic stem cells. Nature 2014; 505: 327-334.

2 Calvi LM, Adams GB, Weibrecht KW, Weber JM, Olson DP, Knight MC et al. Osteoblastic cells regulate the haematopoietic stem cell niche. Nature 2003; 425 : 841-846.

3 Mendez-Ferrer S, Michurina TV, Ferraro F, Mazloom AR, MacArthur BD, Lira SA et al. Mesenchymal and haematopoietic stem cells form a unique bone marrow niche. Nature 2010; 466: 829-U59.

4 Visnjic D, Kalajzic Z, Rowe DW, Katavic V, Lorenzo J, Aguila HL. Hematopoiesis is severely altered in mice with an induced osteoblast deficiency. Blood 2004; 103: 3258-3264

5 Adams GB, Chabner KT, Alley IR, Olson DP, Szczepiorkowski ZM, Poznansky MC et al. Stem cell engraftment at the endosteal niche is specified by the calciumsensing receptor. Nature 2006; 439: 599-603.

6 Pinho S, Lacombe J, Hanoun M, Mizoguchi T, Bruns I, Kunisaki Y et al. PDGFR alpha and CD51 mark human Nestin(+) sphere-forming mesenchymal stem cells capable of hematopoietic progenitor cell expansion. J Exp Med 2013; 210: 1351-1367.

7 Greenbaum A, Hsu YMS, Day RB, Schuettpelz LG, Christopher MJ, Borgerding JN et al. CXCL12 in early mesenchymal progenitors is. required for haematopoietic stem-cell maintenance. Nature 2013; 495: 227-230.

8 Mizoguchi T, Pinho S, Ahmed J, Kunisaki Y, Hanoun M, Mendelson A et al. Osterix marks distinct waves of primitive and definitive stromal progenitors during bone marrow development. Dev Cell 2014; 29: 340-349.

9 Lymperi S, Ersek A, Ferraro F, Dazzi F, Horwood NJ. Inhibition of osteoclast function reduces hematopoietic stem cell numbers in vivo. Blood 2011; 117: 1540-1549.

10 Miyamoto K, Yoshida S, Kawasumi M, Hashimoto K, Kimura T, Sato Y et al. Osteoclasts are dispensable for hematopoietic stem cell maintenance and mobilization. J Exp Med 2011; 208: 2175-2181.

11 Soki FN, Li X, Berry J, Koh A, Sinder BP, Qian X et al. The effects of zoledronic acid in the bone and vasculature support of hematopoietic stem cell niches. J Cell Biochem 2013; 114: 67-78.

12 Mansour A, Abou-Ezzi G, Sitnicka E, Jacobsen SEW, Wakkach A, Blin-Wakkach C. Osteoclasts promote the formation of hematopoietic stem cell niches in the bone marrow. J Exp Med 2012; 209: 537-549.

13 Ludin A, Itkin T, Gur-Cohen S, Mildner A, Shezen E, Golan K et al. Monocytesmacrophages that express alpha-smooth muscle actin preserve primitive hematopoietic cells in the bone marrow. Nat Immunol 2012; 13: 1072-1082.

14 Winkler IG, Sims NA, Pettit AR, Barbier V, Nowlan B, Helwani F et al. Bone marrow macrophages maintain hematopoietic stem cell (HSC) niches and their depletion mobilizes HSCs. Blood 2010; 116: 4815-4828.

15 Hoggatt J, Singh P, Sampath J, Pelus LM. Prostaglandin E-2 enhances hematopoietic stem cell homing, survival, and proliferation. Blood 2009; 113: 5444-5455.

16 Cho SW, Soki FN, Koh AJ, Eber MR, Entezami P, Park SI et al. Osteal macrophages support physiologic skeletal remodeling and anabolic actions of parathyroid hormone in bone. Proc Natl Acad Sci USA 2014; 111: 1545-1550.

17 Siegel G, Kluba T, Hermanutz-Klein U, Bieback K, Northoff H, Schafer R. Phenotype, donor age and gender affect function of human bone marrowderived mesenchymal stromal cells. BMC Med 2013, 11

18 Maijenburg MW, Kleijer M, Vermeul K, Mul EPJ, van Alphen FPJ, van der Schoot CE et al. The composition of the mesenchymal stromal cell compartment in human bone marrow changes during development and aging. Haematologica 2012; 97 : 179-183. 
19 Tormin A, Li O, Brune JC, Walsh S, Schutz B, Ehinger M et al. CD146 expression on primary nonhematopoietic bone marrow stem cells is correlated with in situ localization. Blood 2011; 117: 5067-5077.

20 Ye L, Fan ZP, Yu B, Chang J, Al Hezaimi K, Zhou XD et al. Histone demethylases KDM4B and KDM6B promote osteogenic differentiation of human MSCs. Cell Stem Cell 2012; 11: 50-61.

21 Choumerianou DM, Martimianaki G, Stiakaki E, Kalmanti L, Kalmanti M, Dimitriou H. Comparative study of stemness characteristics of mesenchymal cells from bone marrow of children and adults. Cytotherapy 2010; 12: 881-887.

22 Jung YG, Song JH, Shiozawa Y, Wang JC, Wang Z, Williams B et al. Hematopoietic stem cells regulate mesenchymal stromal cell induction into osteoblasts thereby participating in the formation of the stem cell niche. Stem Cells 2008; 26: 2042-2051.

23 Whitfield JF. Parathyroid hormone (PTH) and hematopoiesis: new support for some old observations. J Cell Biochem 2005; 96: 278-284.

24 Petrova NV, Svinareva DA, Nifontova IN, Momotyuk KS, Savchenko VG, Drize NI. Stromal regulation of hemopoietic stem cells in long-term human bone marrow tissue cultures under the effect of parathyroid hormone. Bull Exp Biol Med 2006 142: $527-530$

25 Lee JH, Hwang KJ, Kim MY, Lim YJ, Seol IJ, Jin HJ et al. Human parathyroid hormone increases the mRNA expression of the IGF system and hematopoietic growth factors in osteoblasts, but does not influence expression in mesenchymal stem cells. J Pediatr Hematol Oncol 2012; 34: 491-496.

26 Cho SW, Pirih FQ, Koh AJ, Michalski M, Eber MR, Ritchie K et al. The soluble interleukin-6 receptor is a mediator of hematopoietic and skeletal actions of parathyroid hormone. J Biol Chem 2013; 288: 6814-6825.

27 Krishnan V, Bryant HU, MacDougald OA. Regulation of bone mass by Wnt sig naling. J Clin Invest 2006; 116: 1202-1209.

28 Boland GM, Perkins G, Hall DJ, Tuan RS. Wnt 3a promotes proliferation and suppresses osteogenic differentiation of adult human mesenchymal stem cells. $J$ Cell Biochem 2004; 93: 1210-1230.

29 Glass DA, Bialek P, Ahn JD, Starbuck M, Patel MS, Clevers H et al. Canonical Wnt signaling in differentiated osteoblasts controls osteoclast differentiation. Dev Cell 2005; 8: 751-764.

30 Baksh D, Tuan RS. Canonical and non-canonical wnts differentially affect the development potential of primary isolate of human bone marrow mesenchymal stem cells. J Cell Physiol 2007; 212: 817-826.

31 Cho SW, Yang JY, Sun HJ, Jung JY, Her SJ, Cho HY et al. Wnt inhibitory factor (WIF)-1 inhibits osteoblastic differentiation in mouse embryonic mesenchymal cells. Bone 2009; 44: 1069-1077.

32 Maeda K, Kobayashi Y, Udagawa N, Uehara S, Ishihara A, Mizoguchi T et al. Wnt5a-Ror2 signaling between osteoblast-lineage cells and osteoclast precursors enhances osteoclastogenesis. Nat Med 2012; 18: 405-U166.

33 Churchman SM, Ponchel F, Boxall SA, Cuthbert R, Kouroupis D, Roshdy T et al. Transcriptional profile of native CD271+ multipotential stromal cells: evidence for multiple fates, with prominent osteogenic and wnt pathway signaling activity. Arthritis Rheum 2012; 64: 2632-2643.

34 Vukicevic S, Grgurevic L. BMP-6 and mesenchymal stem cell differentiation. Cytokine Growth Factor Rev 2009; 20: 441-448.

35 Simic P, Culej JB, Orlic I, Grgurevic L, Draca N, Spaventi R et al. Systemically administered bone morphogenetic protein- 6 restores bone in aged ovariectomized rats by increasing bone formation and suppressing bone resorption. J Biol Chem 2006; 281: 25509-25521.

36 Seib FP, Franke M, Jing D, Werner C, Bornhauser M. Endogenous bone morphogenetic proteins in human bone marrow-derived multipotent mesenchymal stromal cells. Eur J Cell Biol 2009; 88: 257-271.

37 del Toro R, Mendez-Ferrer S. Autonomic regulation of hematopoiesis and cancer. Haematologica 2013; 98: 1663-1666.

38 Shiozawa $\mathrm{Y}$, Jung $\mathrm{YH}$, Ziegler AM, Pedersen EA, Wang JH, Wang Z et al. Erythropoietin couples hematopoiesis with bone formation. Plos One 2010; 5 e10853.

39 Sun HL, Jung $\mathrm{YH}$, Shiozawa $\mathrm{Y}$, Taichman RS, Krebsbach PH. Erythropoietin modulates the structure of bone morphogenetic protein 2-engineered cranial bone. Tissue Eng Pt A 2012; 18: 2095-2105.

40 Kim J, Jung YH, Sun HL, Joseph J, Mishra A, Shiozawa Y et al. Erythropoietin mediated bone formation is regulated by mTOR signaling. J Cell Biochem 2012 113: $220-228$.

41 Singbrant S, Russell MR, Jovic T, Liddicoat B, Izon DJ, Purton LE et al. Erythropoietin couples erythropoiesis, B-lymphopoiesis, and bone homeostasis within the bone marrow microenvironment. Blood 2011; 117: 5631-5642.

42 Nair AM, Tsai YT, Shah KM, Shen JH, Weng H, Zhou J et al. The effect of erythropoietin on autologous stem cell-mediated bone regeneration. Biomaterials 2013; 34: 7364-7371.
43 Koh SH, Noh MY, Cho GW, Kim KS, Kim SH. Erythropoietin increases the motility of human bone marrow-multipotent stromal cells (hBM-MSCs) and enhances the production of neurotrophic factors from hBM-MSCs. Stem Cells Dev 2009; 18 411-421.

44 Rankin EB, Wu C, Khatri R, Wilson TLS, Andersen R, Araldi E et al. The HIF signaling pathway in osteoblasts directly modulates erythropoiesis through the production of EPO. Cell 2012; 149: 63-74.

45 Papaemmanuil E, Gerstung M, Malcovati L, Tauro S, Gundem G, Van Loo P et al. Clinical and biological implications of driver mutations in myelodysplastic syndromes. Blood 2013; 122: 3616-3627.

46 Malcovati L, Papaemmanuil E, Bowen DT, Boultwood J, Della Porta MG, Pascutto $\mathrm{C}$ et al. Clinical significance of SF3B1 mutations in myelodysplastic syndromes and myelodysplastic/myeloproliferative neoplasms. Blood 2011; 118 6239-6246.

47 Starczynowski DT, Kuchenbauer F, Argiropoulos B, Sung S, Morin R, Muranyi A et al. Identification of miR-145 and miR-146a as mediators of the $5 q$-syndrome phenotype. Nat Med 2010; 16: 49-U84.

48 Watanabe-Okochi N, Kitaura J, Ono R, Harada H, Harada Y, Komeno Y et al. AML1 mutations induced MDS and MDS/AML in a mouse BMT model. Blood 2008; 111 4297-4308.

49 Grisendi S, Bernardi R, Rossi M, Cheng K, Khandker L, Manova K et al. Role of nucleophosmin in embryonic development and tumorigenesis. Nature 2005; 437: 147-153.

50 Buonamici S, Li DL, Chi YQ, Zhao R, Wang XR, Brace L et al. EVI1 induces myelodysplastic syndrome in mice. J Clin Invest 2004; 114: 713-719.

51 Lin YW, Slape C, Zhang ZH, Aplan PD. NUP98-HOXD13 transgenic mice develop a highly penetrant, severe myelodysplastic syndrome that progresses to acute leukemia. Blood 2005; 106: 287-295.

52 Muto T, Sashida G, Oshima M, Wendt GR, Mochizuki-Kashio M, Nagata $Y$ et al. Concurrent loss of Ezh2 and Tet2 cooperates in the pathogenesis of myelodysplastic disorders. J Exp Med 2013; 210: 2627-2639.

53 Abdel-Wahab O, Gao J, Adli M, Dey A, Trimarchi T, Chung YR et al. Deletion of Asxl1 results in myelodysplasia and severe developmental defects in vivo. J Exp Med 2013; 210: 2641-2659.

54 Nagamachi A, Matsui $\mathrm{H}$, Asou H, Ozaki Y, Aki D, Kanai A et al. Haploinsufficiency of SAMD9L, an endosome fusion facilitator, causes myeloid malignancies in mice mimicking human diseases with monosomy 7. Cancer Cell 2013; 24: 305-317.

55 Lane SW, Sykes SM, Al-Shahrour F, Shterental S, Paktinat M, Lo Celso C et al. The $\mathrm{Apc}(\mathrm{min})$ mouse has altered hematopoietic stem cell function and provides a model for MPD/MDS. Blood 2010; 115: 3489-3497.

56 Raaijmakers MHGP, Mukherjee S, Guo SQ, Zhang SY, Kobayashi T, Schoonmaker $\mathrm{JA}$ et al. Bone progenitor dysfunction induces myelodysplasia and secondary leukaemia. Nature 2010; 464: 852-U58.

57 Santamaria C, Muntion S, Roson B, Blanco B, Lopez-Villar O, Carrancio S et al. Impaired expression of DICER, DROSHA, SBDS and some microRNAs in mesenchymal stromal cells from myelodysplastic syndrome patients. Haematologica 2012; 97: 1218-1224.

58 Medyouf H, Mossner M, Jann JC, Nolte F, Raffel S, Herrmann C et al. Myelodysplastic cells in patients reprogramm mesenchymal stromal cells to establish a transplantable stem cell niche disease unit. Cell Stem Cell 2014; 14: 824-837.

59 Martin MG, Welch JS, Uy GL, Fehniger TA, Kulkarni S, Duncavage EJ et al. Limited engraftment of low-risk myelodysplastic syndrome cells in NOD/SCID gamma-C chain knockout mice. Leukemia 2010; 24: 1662-1664.

$60 \mathrm{Li} \mathrm{X}$, Deeg HJ. Murine xenogeneic models of myelodysplastic syndrome: an essential role for stroma cells. Exp Hemat 2014; 42: 4-10.

61 Mellibovsky L, Diez A, Serrano S, Aubia J, PerezVila E, Marinoso ML et al. Bone remodeling alterations in myelodysplastic syndrome. Bone 1996; 19: 401-405.

62 Flores-Figueroa E, Arana-Trejo RM, Gutierrez-Espindola G, Perez-Cabrera A Mayani $\mathrm{H}$. Mesenchymal stem cells in myelodysplastic syndromes: phenotypic and cytogenetic characterization. Leukemia Res 2005; 29: 215-224.

63 Flores-Figueroa E, Montesinos JJ, Flores-Guzman P, Gutierrez-Espindola G, Arana-Trejo RM, Castillo-Medina $\mathrm{S}$ et al. Functional analysis of myelodysplastic syndromes-derived mesenchymal stem cells. Leukemia Res 2008; 32: 1407-1416.

64 Soenen-Cornu V, Tourino C, Bonnet ML, Guillier M, Flamant S, Kotb R et al. Mesenchymal cells generated from patients with myelodysplastic syndromes are devoid of chromosomal clonal markers and support short- and long-term hematopoiesis in vitro. Oncogene 2005; 24: 2441-2448.

65 Gayh S, Cadeddu RP, Fröbel J. MDS-derived mesenchymal stromal cells are phenotypically, structurally and epigenetically altered resulting in insufficient stromal support for CD34+ HSPC. Leuk Res 2013; 37: P-230 Ref Type: Abstract.

66 Zhao ZG, Xu W, Yu HP, Fang BL, Wu SH, Li F et al. Functional characteristics of mesenchymal stem cells derived from bone marrow of patients with myelodysplastic syndromes. Cancer Lett 2012; 317: 136-143. 
67 Frisch BJ, Ashton JM, Xing LP, Becker MW, Jordan CT, Calvi LM. Functional inhibition of osteoblastic cells in an in vivo mouse model of myeloid leukemia. Blood 2012; 119: 540-550.

68 Campioni D, Moretti S, Ferrari L, Punturieri M, Castoldi GL, Lanza F. Immunophenotypic heterogeneity of bone marrow-derived mesenchymal stromal cells from patients with hematologic disorders: correlation with bone marrow microenvironment. Haematologica 2006; 91: 364-368.

69 Ferrer RA, Wobus M, List C, Wehner R, Schonefeldt C, Brocard B et al. Mesenchymal stromal cells from patients with myelodyplastic syndrome display distinct functional alterations that are modulated by lenalidomide. Haematologica 2013; 98: 1677-1685.

70 Aanei CM, Flandrin P, Eloae FZ, Carasevici E, Guyotat D, Wattel E et al. Intrinsic growth deficiencies of mesenchymal stromal cells in myelodysplastic syndromes. Stem Cells Dev 2012; 21: 1604-1615.

71 Flores-Figueroa E, Varma S, Montgomery K, Greenberg PL, Gratzinger D. Distinctive contact between $\mathrm{CD} 34+$ hematopoietic progenitors and $\mathrm{CXCL} 12+$ CD271+ mesenchymal stromal cells in benign and myelodysplastic bone marrow. Lab Invest 2012; 92: 1330-1341.

72 Ximeri M, Galanopoulos A, Klaus M, Parcharidou A, Giannikou K, Psyllaki M et al. Effect of lenalidomide therapy on hematopoiesis of patients with myelodysplastic syndrome associated with chromosome $5 q$ deletion. Haematologica 2010; 95: 406-414.

73 Pimenova MA, Kokhno AV, Domracheva E, Drize NI, Manakova T, Konnova M et al. Chromosomal analysis of hematopoietic and stromal progenitor cells in patients with myelodysplastic syndrome (MDS). Leuk Res 2013; 37: P-254 Ref Type: Abstract.

74 Blau O, Baldus CD, Hofmann WK, Thiel G, Nolte F, Burmeister $T$ et al. Mesenchymal stromal cells of myelodysplastic syndrome and acute myeloid leukemia patients have distinct genetic abnormalities compared with leukemic blasts. Blood 2011; 118: 5583-5592.

75 de Oliveira FM, Lucena-Araujo AR, Favarin MD, Palma PVB, Rego EM, Falcao RP et al. Differential expression of AURKA and AURKB genes in bone marrow stromal mesenchymal cells of myelodysplastic syndrome: correlation with G-banding analysis and FISH. Exp Hematol 2013; 41: 198-208.

76 Iwata M, Pillai M, Ramakrishnan A, Hackman RC, Deeg HJ, Opdenakker G et al. Reduced expression of inducible gelatinase $B /$ matrix metalloproteinase- 9 in monocytes from patients with myelodysplastic syndrome: correlation of inducible levels with the percentage of cytogenetically marked cells and with marrow cellularity. Blood 2007; 109: 85-92.

77 Flores-Figueroa E, Gutierrez-Espindola G, Montesinos J, Arana-Trejo RM, Mayani H. In vitro characterization of hematopoietic microenvironment cells from patients with myelodysplastic syndrome. Leuk Res 2002; 26: 677-686.

78 Matsuoka A, Tochigi A, Kishimoto M, Nakahara T, Kondo T, Tsujioka T et al. Lenalidomide induces cell death in an MDS-derived cell line with deletion of chromosome $5 q$ by inhibition of cytokinesis. Leukemia 2010; 24: 748-755

79 Ishibashi M, Tamura H, Ogata K. Disease progression mechanism in myelodysplastic syndromes: insight into the role of the microenvironment. Leuk Res 2011; 35: 1449-1452.

80 Reins J, Mossner M, Neumann M, Platzbecker U, Schumann C, Thiel E et al. Transcriptional down-regulation of the Wnt antagonist SFRP1 in haematopoietic cells of patients with different risk types of MDS. Leuk Res 2010; 34: 1610-1616.

81 Wang H, Fan R, Wang XQ, Wu DP, Lin GW, Xu Y et al. Methylation of Wnt antagonist genes: a useful prognostic marker for myelodysplastic syndrome. Ann Hematol 2013; 92: 199-209.

82 Pavlaki KI, Kastrinaki MC, Batsali A, Demetriadou A, Velegraki M, Mavroudi I et al. Impaired Wnt-pathway signalling and reduced expression of senescenceassociated markers in bone marrow mesenchymal stem cells of patients with myelodysplastic syndromes. Blood 2011; 118: 125-126.

83 Luis TC, Ichii M, Brugman MH, Kincade P, Staal FJT. Wnt signaling strength regulates normal hematopoiesis and its deregulation is involved in leukemia development. Leukemia 2012; 26: 414-421.

84 Schaniel C, Sirabella D, Qiu JJ, Niu XH, Lemischka IR, Moore KA. Wnt-inhibitory factor 1 dysregulation of the bone marrow niche exhausts hematopoietic stem cells. Blood 2011; 118: 2420-2429.

85 Renstrom J, Istvanffy R, Gauthier K, Shimono A, Mages J, Jardon-Alvarez A et al. Secreted frizzled-related protein 1 extrinsically regulates cycling activity and maintenance of hematopoietic stem cells. Cell Stem Cell 2009; 5: 157-167.

86 Fleming HE, Janzen V, Lo Celso C, Guo J, Leahy KM, Kronenberg HM et al. Wnt signaling in the niche enforces hematopoietic stem cell quiescence and is necessary to preserve self-renewal in vivo. Cell Stem Cell 2008; 2: 274-283.

87 Lane SW, Wang YZJ, Lo Celso C, Ragu C, Bullinger L, Sykes SM et al. Differential niche and Wnt requirements during acute myeloid leukemia progression. Blood 2011; 118: 2849-2856.
$88 \mathrm{Qu}$ ZH, Zhang XL, Tang TT, Dai KR. Promotion of osteogenesis through betacatenin signaling by desferrioxamine. Biochem Biophys Res Commun 2008; 370: 332-337.

89 Kode A, Manavalan JS, Mosialou I, Bhagat G, Rathinam CV, Luo N et al. Leukaemogenesis induced by an activating beta-catenin mutation in osteoblasts. Nature 2014; 506: 240-244.

90 Park S, Grabar S, Kelaidi C, Beyne-Rauzy O, Picard F, Bardet V et al. Predictive factors of response and survival in myelodysplastic syndrome treated with erythropoietin and G-CSF: the GFM experience. Blood 2008; 111: 574-582.

91 Frisan E, Pawlikowska P, Pierre-Eugene C, Viallon V, Gibault L, Park S et al. p-ERK $1 / 2$ is a predictive factor of response to erythropoiesis-stimulating agents in low/int-1 myelodysplastic syndromes. Haematologica 2010; 95: 1964-1968.

92 Forejtnikova H, Vieillevoye M, Zermati Y, Lambert M, Pellegrino RM, Guihard S et al. Transferrin receptor 2 is a component of the erythropoietin receptor complex and is required for efficient erythropoiesis. Blood 2010; 116: 5357-5367.

93 Guggenbuhl P, Filmon R, Mabilleau G, Basle MF, Chappard D. Iron inhibits hydroxyapatite crystal growth in vitro. Metabolism 2008; 57: 903-910.

94 Yang Q, Jian JL, Abramson SB, Huang X. Inhibitory effects of iron on bone morphogenetic protein 2-induced osteoblastogenesis. J Bone Miner Res 2011; 26: 1188-1196.

95 Guggenbuhl P, Fergelot P, Doyard M, Libouban H, Roth MP, Gallois Y et al. Bone status in a mouse model of genetic hemochromatosis. Osteoporos Int 2011; 22: 2313-2319.

96 Zarjou A, Jeney V, Arosio P, Poli M, Zavaczki E, Balla G et al. Ferritin ferroxidase activity: a potent inhibitor of osteogenesis. J Bone Miner Res 2010; 25: 164-172.

97 Tsay J, Yang ZW, Ross FP, Cunningham-Rundles S, Lin H, Coleman R et al. Bone loss caused by iron overload in a murine model: importance of oxidative stress. Blood 2010; 116: 2582-2589.

98 Jia P, Xu YJ, Zhang ZL, Li K, Li BY, Zhang W et al. Ferric ion could facilitate osteoclast differentiation and bone resorption through the production of reactive oxygen species. J Orthop Res 2012; 30: 1843-1852.

99 Liu G, Men P, Kenner GH, Miller SC. Therapeutic effects of an oral chelator targeting skeletal tissue damage in experimental postmenopausal osteoporosis in rats. Hemoglobin 2008; 32: 181-190.

100 Lee NK, Choi YG, Baik JY, Han SY, Jeong DW, Bae YS et al. A crucial role for reactive oxygen species in RANKL-induced osteoclast differentiation. Blood 2005; 106: 852-859.

101 Murphy PT, Mitra S, Gleeson M, Desmond R, Swinkels DW. Urinary hepcidin excretion in patients with low grade myelodysplastic syndrome. $\mathrm{Br} J$ Haematol 2009; 144: 451-452.

102 Winder A, Lefkowitz R, Ghoti H, Leiba M, Ganz T, Nemeth E et al. Urinary hepcidin excretion in patients with myelodysplastic syndrome and myelofibrosis. $\mathrm{Br} J$ Haematol 2008; 142: 669-671.

103 Ambaglio I, Malcovati L, Papaemmanuil E, Laarakkers CM, Della Porta MG, Galli A et al. Inappropriately low hepcidin levels in patients with myelodysplastic syndrome carrying a somatic mutation of SF3B1. Haematologica 2013; 98: 420-423.

104 Breda L, Ghoti H, Rivella S, Rechavi G, Cabantchik I, Rachmilewitz E. Expression of genes regulating iron metabolism in hepatocyte cell-line HepG2 induced by sera from MDS patients. Blood 2007; 110: 225B-226BB

105 Masala E, Valencia A, Buchi F, Nosi D, Spinelli E, Gozzini A et al. Hypermethylation of Wnt antagonist gene promoters and activation of Wnt pathway in myelodysplastic marrow cells. Leuk Res 2012; 36: 1290-1295.

106 Delgado-Calle J, Arozamena J, Perez-Lopez J, Bolado-Carrancio A, Sanudo C, Agudo $\mathrm{G}$ et al. Role of BMPs in the regulation of sclerostin as revealed by an epigenetic modifier of human bone cells. Mol Cell Endocrinol 2013; 369: 27-34.

107 Dussiot M, Maciel TT, Fricot A, Chartier C, Negre O, Veiga J et al. An activin receptor IIA ligand trap corrects ineffective erythropoiesis in beta-thalassemia. Nat Med 2014; 20: 398-+.

108 Lotinun S, Pearsall RS, Davies MV, Marvell TH, Monnell TE, Ucran J et al. A soluble activin receptor Type IIA fusion protein (ACE-011) increases bone mass via a dual anabolic-antiresorptive effect in Cynomolgus monkeys. Bone 2010; 46: 1082-1088.

109 Mulivor AW, Barbosa D, Kumar R, Sherman ML, Seehra J, Pearsall RS. RAP-011, a soluble activin receptor type lla murine lgG-Fc fusion protein, prevents chemotherapy induced anemia. Blood 2009; 114: 72.

110 Ruckle J, Jacobs M, Kramer W, Pearsall AE, Kumar R, Underwood KW et al. Single-dose, randomized, double-blind, placebo-controlled study of ACE-011 (ActRIIA-lgG1) in postmenopausal women. J Bone Miner Res 2009; 24: 744-752.

111 Abdulkadyrov KM, Salogub GN, Khuazheva NK, Sherman ML, Laadem A, Bager R et al. Sotatercept in patients with osteolytic lesions of multiple myeloma. Br J Haemat 2014; 165: 814-823. 
112 Carrancio S, Markovics J, Wong P, Leisten J, Castiglioni P, Groza MC et al. An activin receptor IIA ligand trap promotes erythropoiesis resulting in a rapid induction of red blood cells and haemoglobin. Br J Haematol 2014; 165: 870-882.

113 lancu-Rubin C, Mosoyan G, Wang JP, Kraus T, Sung V, Hoffman R. Stromal cell-mediated inhibition of erythropoiesis can be attenuated by sotatercept (ACE-011), an activin receptor type II ligand trap. Exp Hematol 2013; 41: 155-166.

114 Suragani RN, Cadena SM, Cawley SM, Sako D, Mitchell D Li R et al. Transforming growth factor- $\beta$ superfamily ligand trap ACE- 536 corrects anemia by promoting late-stage erythropoiesis. Nat Med 2014; 20: 408-414.

115 Platzbecker U, Germing U, Giagounidis A, Götze K, Kiewe P, Mayer K. ACE-536 increases hemoglobin levels in patients with low or intermediate-1 risk myelodysplastic syndromes (MDS): preliminary results from phase 2 study. 19th Congress of European Hematology Association, S1296 2014; Ref Type: Abstract.

116 Gattermann N, Finelli C, Della Porta M, Fenaux P, Stadler M, Guerci-Bresler A et al. Hematologic responses to deferasirox therapy in transfusion-dependent patients with myelodysplastic syndromes. Haematologica 2012; 97: 1364-1371.

117 Lu WY, Zhao MF, Rajbhandary S, Xie F, Chai X, Mu J et al. Free iron catalyzes oxidative damage to hematopoietic cells/mesenchymal stem cells in vitro and

suppresses hematopoiesis in iron overload patients. Eur J Haematol 2013; 91: 249-261.

118 Li HH, Rybicki AC, Suzuka SM, von Bonsdorff L, Breuer W, Hall CB et al. Transferrin therapy ameliorates disease in beta-thalassemic mice. Nat Med 2010; 16: 177-U80.

119 Nicolas G, Viatte L, Lou DQ, Bennoun M, Beaumont C, Kahn A et al. Constitutive hepcidin expression prevents iron overload in a mouse model of hemochromatosis. Nat Genet 2003; 34: 97-101.

120 Babitt JL, Huang FW, Xia Y, Sidis Y, Andrews NC, Lin HY. Modulation of bone morphogenetic protein signaling in vivo regulates systemic iron balance. J Clin Invest 2007; 117: 1933-1939.

(c) (i) $(-)$ This work is licensed under a Creative Commons Attributioncc. Non NC ND Nomercial-NoDerivs 4.0 International License. The images or other third party material in this article are included in the article's Creative Commons license, unless indicated otherwise in the credit line; if the material is not included under the Creative Commons license, users will need to obtain permission from the license holder to reproduce the material. To view a copy of this license, visit http:// creativecommons.org/licenses/by-nc-nd/4.0/ 